\title{
Slovo Cubano: el vocablo soviético en el español de Cuba
}

\author{
Slovo Cubano: the Soviet Word in the Spanish of Cuba
}

\section{VLADIMIR SMITH-MESA}

University College London·v.a.smithmesa@ucl.ac.uk

Comenzó sus estudios en Rusia y los terminó en la Universidad de La Habana, donde se graduó en Bibliotecología y Ciencias de la Información en 1995. En 2011, se doctoró en University College London con su tesis "KinoCuban, the significance of Soviet and East European cinemas for the Cuban moving image". Actualmente trabaja como catalogador para la UCL- School of Slavonic and East European Studies Library en Londres. Dr Smith-Mesa es el fundador del UCL Festival of the Moving Image.

RECIBIDO: 10 DE FEBRERO DE 2015

ACEPTADO: 3 DE JUNIO DE 2015

Resumen: ¿Se puede definir una nostalgia cubana por lo soviético? Indagando sobre su estética, entendida como percepción, "Slovo Cubano" intenta responder a este interrogante. Enfocándose en los rusismos-sovietismos, que llegaron a nuestra isla en diferentes épocas. Estas palabras ya son parte de nuestro catauro de extranjerismos; fragmento significativo en la historia de la adopción lingüística en el español cubanocaribeño. Estos vocablos no son sólo referencias filológicas, símbolos de una oralidad y escritura muy particulares, también son evidencias históricas, que actúan como códigos de acceso a la experiencia cultural soviética. "Slovo Cubano" intenta confirmar que desde 1961 hasta 1991, Cuba fue, por excelencia, el centro diseminador de lo eslavo, el gran transculturador de lo ruso-soviético en el universo de habla hispana, en las Américas y en el llamado Tercer Mundo.

Palabras Clave: Slovo Cubano, rusismo, sovietismo, adopción lingüística, Cuba, nostalgia
Abstract: Can we define a Cuban nostalgia for the Soviet past? "Slovo Cubano" attempts to answer this question by inquiring about aesthetics, understood as perception. This paper focuses on Russian and Soviet words that arrived in Cuba at different times. They are an essential part of our Catauro of foreign words; a significant fragment in the process of adoption of alien terms in the Cuban-Spanish language. These words are not only philological references, they are also the historical evidence of a unique oral and written history because they act as access codes to the Soviet cultural experience. "Slovo Cubano" attempts to confirm that from 1961-1991, Cuba was, par excellence, the disseminator, the Slavonic centre, the great 'transculturador' of Russian \& Soviet terms in the Americas and the so-called Third World.

Key Words: Slovo Cubano, Russian words, Soviet words, linguistic adoption, Cuba, Cuban nostalgia. 
"Todo el mundo estudiaba inglés, menos nosotros que estudiábamos ruso", dijo el Comandante, el ex gobernante cubano, en tono de choteo, durante el lanzamiento del libro de memorias Fidel Castro: Guerrillero del tiempo, seguido por una ola de carcajadas en la audiencia. ${ }^{1}$ Esta afirmación suya es interesante por el tono jocoso del comentario, al referirse a la cuestión soviética, tema que fue de gran respeto y solemnidad para él hasta 1991. Ciertamente, cuando medio mundo continuaba estudiando inglés, los cubanos estuvimos aprendiendo ruso durante su extendido mandato dictatorial. Su afirmación es en extremo sugestiva por el hecho histórico que fue precisamente su gobierno quien impuso el estudio de la lengua rusa, en su versión soviética, en los programas educativos. Este idioma fue considerado esencial, pues era la lengua usada en la colaboración con la extinta URSS y los países del bloque del este. En aquel entonces, el ruso era para Fidel Castro, la lengua del porvenir, respondiendo a su propio slogan: 'el futuro pertenece por entero al socialismo'. ${ }^{2}$ Nunca antes en la historia del hemisferio occidental se hizo tanto para popularizar y enseñar la lengua rusa y la cultura soviética. Las gestiones realizadas no tienen precedentes, ni en su forma, ni en su contenido, ni en su extensión. Parecía como una versión sovietizada del paneslavismo para las Américas.

Hoy sabemos que el ruso impartido en nuestras aulas fue un ruso-sovietizado. El vocablo aprendido por las últimas generaciones de cubanos, no poseía la claridad, la armonía de esa primera palabra original rusa, nacida de una poética singular, que transitaba desde Pushkin hasta Andrei Belyi, pasando por Tolstoi y Dostoievski. El ruso que nos llegó -y se popularizó desde 1961 hasta el 91 a nivel nacional- todavía llevada la máscara del realismo socialista y ya estaba contaminado con un léxico politizado, ceremonioso en extremo, surgido de un dialecto autóctono de la URSS. Este vocablo era hijo genuino de la ideología marxista-leninista. Sus frases, su argot afectaron a todas las demás lenguas que estaban bajo su atmósfera; dándoles un carácter solemne y artificioso.

Es oportuno recordar que La Constitución, ley fundamental del país, fue adoptada el 24 de febrero de 1976. En ésta se decreta que en Cuba: "El Partido Comunista, martiano y marxistaleninista, vanguardia organizada de la nación cubana, es la fuerza dirigente superior de la sociedad y del Estado, que organiza y orienta los esfuerzos comunes hacia los altos fines de la construcción del

\footnotetext{
${ }^{1}$ Las palabras de Fidel Castro fueron transmitidas el 7 de febrero del 2012, de manera diferida, en el horario de la Mesa Redonda de la televisión cubana. El acto tuvo lugar el viernes de la semana anterior en el Palacio de las Convenciones y se extendió por seis horas, en presencia de una selecta audiencia de figuras del gobierno, intelectuales, artistas y periodistas. Katiuska Blanco, la autora de esta biografía, ha publicado una serie de libros sobre Fidel Castro.

${ }^{2}$ En el Discurso pronunciado en el Kremlin por el 50 aniversario de la URSS (22.12.1972) Fidel Castro expresión fue: "que el futuro pertenece por entero al socialismo ya nadie lo puede dudar". Para leer en internet los discursos de Fidel Castro (desde 1959 hasta el 2008, algunos de ellos traducidos a diferentes idiomas), ver aquí .
} 
socialismo y el avance hacia la sociedad comunista". ${ }^{3}$ En la Carta Magna cubana se reconoce al partido comunista como la institución política central, regente y única de toda la nación. Esta constitución incluye palabras, expresiones impensables en la Cuba de principios del siglo XX, como: comunista, marxista-leninista, socialista... ¿cómo llegaron estas palabras al español de Cuba? Tomando en consideración la afirmación inicial de El comandante - ¿se puede definir una nostalgia cubana por lo soviético? Indagando sobre su estética, entendida como percepción, Slovo Cubano intenta responder a esta interrogante. Enfocándose en los rusismos-sovietismos, que llegaron a nuestra isla, en diferentes épocas. Estas palabras ya son parte de nuestro catauro de extranjerismos; fragmento significativo en la historia de la adopción lingüistica en el español cubano-caribeño. ${ }^{4} \mathrm{El}$ presente texto intenta confirmar que desde 1961 hasta 1991, Cuba fue por excelencia, el centro diseminador de lo eslavo, el gran transculturador de lo ruso-soviético en el universo de habla hispana, en las Américas y en el llamado Tercer Mundo.

Según el Diccionario de la lengua española (DRAE), nostalgia es 'tristeza melancólica originada por el recuerdo de una dicha perdida'. El presente estudio toma prestado de la antropología, la noción de 'cultura material'. De sus estudios sobre memoria y temporalidad, donde se presenta el tema de la nostalgia como fenómeno político y social. ${ }^{5}$ Planteamos que el vocablo puede considerarse también un 'objeto', el cual ha sido creado por una persona (o grupo de personas). Sin dudas, una palabra posee su propia historia, cuya complejidad se enriquece en el tiempo. Una palabra es también una imagen, en constante movimiento, un "objeto", que proporciona una forma íntegra - y arriesgada - del conocimiento. Su riesgo radica en el hecho de que sólo refleja los puntos de vista de quienes la crearon. En nuestro caso, se mostrará que el vocablo soviético tuvo una ‘dicha’ ideológica, marxista-leninista, una existencia política.

El presente estudio complementa la interpretación de la experiencia soviética en Cuba, experimento cultural único en las Américas, en el Caribe. Es nuestro objetivo mostrar el carácter mediático de esta adopción lingüística, o sea, el importante rol jugado por los medios de comunicación, en este proceso de asimilación. Los cubanos no leían libros pero si la prensa: diarios, revistas sociales y con el paso del tiempo, fueron adictos a la televisión. En aquel entonces, "había en La Habana más casas de citas que casas editoriales", como bien precisara un ensayista cubano (Cabrera Infante, 1991: 523). En este ensayo se presentará la cronología que explica el por qué,

\footnotetext{
${ }^{3}$ Se puede consultar aquí La Constitución de la República de Cuba, Ley Fundamental de la República de Cuba', fue adoptada el 24 de febrero de 1976.

4 Adopción lingüística es un término que propuso el filólogo Américo Castro Quesada en 1924, así como el de importación lingüística, para sustituir la denominación préstamo lingüístico ya que cuando un elemento de una lengua es adquirido por otra, nunca se devuelve. Ver: "Sintaxis histórica del español y cambio lingüístico: nuevas perspectivas”, editado por Johannes Kabatek, en Lingüística Iberoamericana (2008), (referencia: pp. 7-16, p. 56).

${ }^{5}$ Sobre este tema ver Anthropology and Nostalgia, editado por Olivia Angé y David Berliner New York: Berghahn Books (2014).
} 
cómo se adoptaron los principios esenciales de esta lingüística ruso-soviética. Una de sus características ha sido su gran interés, su reconocimiento enfático del carácter social de la lengua y la preocupación palpable por el estudio de su semántica. Todo esto contribuyó elocuentemente a las erudiciones sociolingüísticas y de sociología del lenguaje, creaciones singulares del pensamiento ruso-soviético, registradas por Jakobson, Bakhtin, Lotman, Gasparov, entre tantos otros. ${ }^{6}$

Nuestro texto, expone cómo se utilizó lo ruso-soviético para instruir, definir conceptos, para diseminar a nivel nacional ideas políticas-sociales, económicas, educativas, y propuestas estéticas soviéticas (el llamado 'realismo socialista'). Estas se insertaron en el discurso socio-político de la revolución cubana (1961-91), versión caribeña del marxismo-leninismo.

La presencia del vocablo soviético en el español cubano no sólo debe ser vista de manera estricta desde la cuestión literaria, la palabra escrita o desde la literatura de ficción que pudiera encerrarla en los estrechos marcos de la poesía y la prosa. Esta peculiar palabra llegada desde el bloque soviético también tuvo ritmo, repetición y periodicidad, que son justamente los elementos caracterizadores de la oralidad. Ella se sumergió y afectó todos los aspectos de la sociedad cubana. Por lo mismo, no se puede evaluar en un solo texto investigativo el impacto de lo soviético en su totalidad. En estos apuntes introductorios, nos referimos en términos generales a los hechos y factores; identificando nombres y prácticas que se llevaron a cabo en la sociedad cubana, para dar a conocer a 'la otra Europa' y en particular al bloque soviético, a través de una serie de textos, escogidos bajo la lupa ideológica. En el presente estudio haremos referencia a textos eslavos, originalmente escritos en cirílico.

Es vital preponderar el año: 1961. Cuando ocurrió la declaración del carácter pro-soviético del proceso socialista cubano. Aquí, los mentores culturales de la revolución fusionaban 'oficialmente' dos discursos que fueron, hasta ese momento, bien distantes: el nacionalismo cubano con el marxismo-leninismo. ${ }^{7}$ Esta fusión, ocurrida en los espinosos espacios de la Guerra Fría, trajo como consecuencia inmediata la introducción masiva de palabras, términos y conceptualizaciones soviéticas en el español cubano. Precisamente, en este hecho radica el legado político del Comandante, según sus propias palabras: 'creo que mi contribución a la Revolución Cubana consiste en haber realizado una síntesis de las ideas de Martí y del marxismo-leninismo, y haberla

\footnotetext{
${ }^{6}$ La figura dominante dentro de la lingüística soviética era Nikolái Marr, hasta el día que Stalin lo excomulgó, sobre este tema ver Russian and Soviet sociolinguistics and taboo varieties of the Russian language: (argot, jargon, slang, and "mat") (Slavistische Beitrage) de Wilhelm von Timroth, Sobre este topico ver Craig Brandist, 'The Origin of Soviet Sociolinguistics', Journal of Sociolinguistics 7(2) 2003. Ver también Politics and the Theory of Language in the USSR, 1917-1938: the Birth of Sociological Linguistics, editado por Craig Brandist y Katya Chown (London: Anthem Press, 2010). Como gran testimonio del trabajo divulgativo en tiempos de la revolución Cuban ver los dos tomos, selección y traducción del ensayista Desiderio Navarro, Elpensamiento cultural ruso en 'Criterios' (La Habana, 2009.

${ }^{7}$ Un interesante estudio sobre el tema es: Una revolución martiana y marxista de José Cantón Navarro (La Habana: Centro de Estudios Martianos, 2008).
} 
aplicado consecuentemente a nuestra lucha' (Castro, 1985: 163-164). Sin dudas, el Comandante se le debe reconocer como el último bolchevique, el gran transculturador de lo soviético en el mundo hispano.

\section{El español de Cuba}

Gracias a muchos estudios lingüísticos, podemos afirmar que el español cubano comparte la mayoría de las características del español caribeño. Este se reconoce por la notable influencia de los dialectos canario y andaluz, por el gran influjo de términos africanos y de palabras del taíno, lengua indígena. Quienes más notan este fenómeno son los estudiantes del español, quienes al encontrarse con el habla cubana, suelen sentir que se enfrentan a todo un nuevo idioma desconocido, para el cual les es casi inservible el modelo del español Ibérico. ${ }^{8}$

Existen numerosos estudios dedicados al español cubano. Estos datan desde la época colonial hasta nuestros días. Desde la obra pionera de Esteban Pichardo Diccionario provincial de voces cubanas (1836), pasando por las bibliografías de Bachiller y Morales, Un catauro de cubanismos (1923) de Fernando Ortiz, el Léxico cubano (1928-46) de Juan Miguel Dihigo, hasta el Estudios sobre el español de Cuba (1971) de Humberto López Morales. Todas estas obras demuestran una inquietud por distinguir y analizar los diferentes elementos que componen nuestra habla. Hasta hoy, los estudios van desde las lenguas aborígenes hasta los anglicismos. Los eslavismos, rusismos y sovietismos no han sido estudiados todavía con la atención, con el debido espacio y tiempo que el tema demanda. ${ }^{9}$

Contrapunteo cubano del tabaco y del azúcar (1940) es la obra cumbre de don Fernando Ortiz (1881 - 1969). Este libro es la gran tesis sobre la cultura cubana y una original contribución a los estudios postcoloniales. Sin dudas, como bien afirmara el crítico literario Ángel Rama, la sensibilidad de Ortiz por el espíritu de la lengua, hace de sus libros, y de esta publicación en particular, una

\footnotetext{
${ }^{8}$ Sobre el español caribeño vea: Bibliografía sobre el español del Caribe hispánico de Rafael Ángel Rivas D. (Caracas: Instituto Universitario Pedagógico de Caracas, 1985), Estudios de lexicología antillana de José Juan Arrom (La Habana: Casa de las Américas, 1980) y El español del Caribe de Humberto López Morales (Madrid: Editorial MAPFRE, 1992), ver el libro de Luis A. Ortiz López, El Caribe hispánico, perspectivas lingǘsticas actuales: homenaje a Manuel Álvarez Nazario (Madrid: Iberoamericana, 1999), entre tantos otros.

${ }^{9}$ Vea Estudios sobre el español de Cuba de Humberto López Morales (New York: Las Américas 1971), Nuevo catauro de cubanismos de Fernando Ortiz (La Habana: Editorial de Ciencias Sociales, 1974), Del español de Cuba : apuntes lexicológicos de Aurora M. Camacho Barreirob (Ciudad de La Habana : Editorial Científico-Técnica, 1994), Diccionario del español de Cuba : español de Cuba-español de España, editado por Günther Haensch (Madrid: Gredos, 2000); Las lenguas indigenas de América y el español de Cuba de Sergio Valdés Bernal (La Habana: Editorial Academia, c1991-1993). Artículos como El español en Cuba: Los contactos lingǘsticos y la variación geosociolectal de /-Latin small letter long S/ y /-1/ de Vicente Jesús Figueroa Arencibia, en Revista Internacional de Lingüistica Iberoamericana, 2009 , vol.7 (2), pp.115-144.
} 
experiencia lingüística innovadora. ${ }^{10}$ En su obra Contrapunteo, el etnólogo explica: En Cuba decir siboney, taíno, español, judío, inglés, francés, angloamericano, negro, yucateco, chino y criollo, no significa indicar solamente los diversos elementos formativos de la nación cubana (Ortiz, 2001: 256). ¿Y el elemento eslavo, el ruso, el soviético? ¿Cuándo, por qué, cómo, quién insertó éstos en el tronco de la identidad cultural cubana? Slovo Cubano acepta la conceptualización transcultural y asume su perspectiva como la más apropiada para estudiar los hechos culturales, entre ellos, la experiencia lingüística. Estos apuntes utilizan un contrapunteo diferente, si antes fue entre el tabaco y el azúcar, el actual que nos ocupa, es entre el español cubano y el vocablo soviético, que nos llegó desde el ruso fundamentalmente.

\section{Metodología}

El sociólogo polaco Bronisław Malinowski (1884-1942), en su introducción al libro de Ortiz, precisa que la transculturación es un "proceso de toma y daca”. El dar y el recibir son dos acciones desiguales que van en direcciones contrapuestas, dentro de un mismo proceso de intercambio, dinámico y continuo, en el cual ambas partes de la ecuación resultan modificadas. ${ }^{11}$ Por obvias razones, nuestros apuntes se enfocan en lo rusismos del español de Cuba (el recibir) y no en los cubanismos en la lengua rusa (el dar). La bibliografía bilingüe Russian Literature in the Hispanic World (1972) de George O. Schanzer es una importante obra de referencia, que indaga los comienzos de la difusión de obras literarias rusas en el mundo hispánico, desde España hasta las Américas. Esta obra es una excelente manera de observar la cronología del vocablo ruso y su variación soviética en nuestro universo. Desafortunadamente, el autor afirma que el caso cubano fue excluido, sin dar más explicaciones al respecto. A pesar de esto, este libro nos permite comparar fechas y datos que reafirman a la experiencia cubano-soviético, como un fenómeno lingüístico único en el hemisferio occidental de la hispanidad, por lo que bien merece un capítulo aparte. Una monografía que repara parcialmente este problema es la Bibliografía de autores soviéticos: libros y folletos publicados en Cuba (1959-1977). Ambas publicaciones testimonian la necesidad de actualizar y unificar estos estudios, pues son los únicos dedicados a esta temática y se remontan a los años setentas. Por todo esto, Slovo Cubano llena un espacio vacío. Estos apuntes también forman

\footnotetext{
${ }^{10}$ En 1982, el crítico literario uruguayo Ángel Rama publica su estudio Transculturación narrativa en América Latina, obra pionera donde se aplica el valor explicativo de la perspectiva transcultural de Ortiz en el análisis histórico de la literatura latinoamericano, en su relación con la península Ibérica. En este trabajo suyo, Rama identifica además los nombres de los grandes transculturadores de la hispanidad en las Américas.

${ }^{11}$ Esta introducción fue escrita originalmente en inglés por Bronisław Kasper Malinowski. Consultar mi ensayo

"Transcultural Letters: The Correspondence of Bronisław Malinowski and Fernando Ortiz".
} 
parte de la naciente bibliografía e interés en los estudios comparativos eslavo-latinoamericanos, que se enfocan fundamentalmente en los temas rusos del período soviético.

Existen numerosas ilustraciones, dedicadas a la lingüística hispánica, donde se analiza su historia, se describe la estructura fónica, morfológica y sintáctica del español (sonidos, palabras y oraciones) en sus diversas versiones y dialectos. ${ }^{12}$ La contribución de Slovo Cubano puede explicarse por la ausencia de una información actualizada sobre el fenómeno de adopción lingüística proveniente del ruso. En el nuestro, utilizamos como objeto de estudio el excepcional caso cubano. Sobre la lengua rusa, hay muchos libros académicos que explican muy bien su historia y en particular su periodo soviético. Hay también grandes obras de ficción: poemas, cuentos, novelas, las llamabas 'grandes distopías literarias' (en relación a lo soviético), que sintetizan de igual manera, creativa y válida, su experimento lingüístico. Por eso, para describir, analizar, acercarnos a este, no sólo la historia nos servirá, pero también la imaginación. Una novela como Nosotros de Evgeny Zamyatin es importante de mencionar por su influencia en 1984, obra literaria del inglés George Orwell. En ella, se habla de la neo-lengua o nueva habla (newspeak en inglés). Toda esta literatura de ficción evidencia lo que Alfonso Reyes, el mexicano universal, una vez explicó: "La imaginación, la loca de la casa, vale tanto como la historia para la interpretación de los hechos humanos...” (Reyes: 1991: 227).

\section{Extranjerismos (rusismos-sovietismos)}

En lingüística, un extranjerismo es un vocablo o expresión que un idioma toma de otro, sea para llenar un vacío semántico (lo innominado) o como alternativa a otras expresiones ya existentes en la lengua de destino, o simplemente palabras de otros idiomas que hemos adoptado a lo largo de los años. Estos vocablos pueden mantener su grafía y pronunciación original o pueden adaptarse. Los extranjerismos son un caso especial de la adopción lingüística. Este último término también sirve para designar no sólo la adopción de palabras, sino también la aceptación de estructuras gramaticales. Los extranjerismos existen en todos los idiomas. De esta manera, ellos se enriquecen, llenando sus vacíos de designación. Una forma efectiva, donde pueden aludir a objetos, costumbres o realidades nuevas, importadas o no naturalizadas en una cultura. Los exotismos son palabras que denotan personas, animales, vegetales o instituciones que no existen en la lengua receptora. Ejemplos de estos tenemos a palabras como: taiga, mujik, bolshevique. Un xenismo es prácticamente lo mismo: palabras que reflejan una realidad propia de la cultura y lo natural del mundo eslavo, como samovar, caviar. Para todo esto, nos es necesario referirnos al término geopolítico, el cual nos permite acercar personas, naciones, gobiernos a pesar de la gran distancia geográfica y cultural.

\footnotetext{
12 Por una bibliografía actualizada de estos ver Introducción a la lingüistica hispánica 2nd ed, de los autores José Ignacio
} Hualde, Antxon Olarrea y Anna María Escobar (Cambridge: Cambridge University Press, 2010). 
La agitación política de principios del siglo XX y los cambios radicales de ideología, dieron al ruso escrito su apariencia moderna en el mundo hispánico. Las propuestas soviéticas en las artes, en las ramas militar, científica y tecnológica (especialmente en la carrera espacial) dieron al ruso un prestigio internacional, si bien a veces de manera resentida. En el español caribeño, en comparación con otros idiomas, como el inglés por ejemplo, muy pocas 'palabras prestadas' o mejor dicho 'vocablos adquiridos' proceden del ruso. ${ }^{13}$ Ciertamente este no es el caso del español en Cuba. No obstante, en los estudios publicados hasta ahora, no existe una investigación académica que sea actualizada, significativa en datos y relevancia. El idioma ruso es sin dudas el más discutido entre los idiomas eslavos, y a nivel mundial uno de los más hablados, teniendo en cuenta el número de parlantes totales en la actualidad. Hasta 1917, fue el único idioma oficial del imperio ruso. Hemos mencionado anteriormente que muchos idiomas, incluyendo el español, contienen palabras tomadas del ruso. Algunas de ellas coexisten en otras lenguas y es difícil concluir si llegaron al español del ruso o, por ejemplo, del ucraniano. Slovo Cubano no intenta llegar a este nivel de precisión, tampoco no observamos el impacto del español nuestro en las lenguas eslavas y en la rusa en particular, durante la era soviética.

¿Cuándo llegó el vocablo ruso a Cuba? Su historia puede dividirse en dos épocas: antes y después de 1961. La división es marcada por la declaración del carácter socialista de la revolución en ese año, indicador del momento histórico que divide no solo la historia del vocablo ruso en Cuba, sino de todas las lenguas eslavas y de la Europa del este (húngaro, rumano, albano, alemán y demás) que llegaron a la isla como parte del proyecto URSS.

\section{Primera Época}

La 'adopción' lingüística desde la lengua rusa, comenzó con los primeros contactos entre la Cuba colonial y la Rusia imperial. En el libro de Moiséev y Egórova. Los rusos en Cuba, se explica que en el primer tercio del siglo XVI, se tuvieron noticias de nuestra isla en lo que entonces era la lejana Moscovia. No sería sin embargo hasta la segunda mitad del siglo XVIII cuando llegaron los primeros viajeros rusos. Nombres como los "mambises": Piotr Streltsov, Nikolai Melentev y Evstafi Konstantinovich, que fueron voluntarios en las guerras de independencia en Cuba; el pintor Vasili Vereshchagin, el campeón del mundo del ajedrez Mikhail Chigorin (1850-1908) y la bailarina Anna

\footnotetext{
${ }^{13}$ Un interesante trabajo comparativo de los extranjerismos en el español del Caribe es el estudio El impacto del inglés en el español puertorriqueño: un análisis comparativo de Carmen Jany (Oxford: Peter Lang, 2001). En internet encontré un breve artículo, con un título relevante para este ensayo, publicado por Fernando Antonio Ruano Faxas: 'Rusismo o Rusismos y Sovietismo o Sovietismos', en el cual se explica que fue: "parte de la conferencia impartida por el filólogo y lingüista cubano Fernando Antonio Ruano Faxas [Internet]. Version 1. ruanofaxas. 2011 Aug 16. Available from: http://ruanofaxas.wordpress.com/article/rusismo-o-rusismos-y-sovietismo-o-19j6x763f3uf8-7/." Este es el único texto de referencia con el cual contamos hasta el momento. Seguramente, deben existir otros estudios sobre el tema, pero ciertamente, hasta hoy, ellos no han logrado ser divulgados de manera efectiva.
} 
Pavlova (1881-1931) se encuentran entre las diversas personalidades de la cultura y las artes rusas, quienes establecieron los primeros contactos personales con Cuba. Sin embargo, para referirse a los inicios de la lengua rusa en Cuba, ninguno de estos nombres tiene la relevancia que alcanza Fyodor Vasilyevich Karzhavin (1745-1812). ${ }^{14}$

Karzhavin fue médico de profesión y es reconocido como el primer ruso que llegó a Cuba. Fue además, escritor, traductor de francés e inglés, editor, bibliófilo apasionado, dueño de una colección de libros únicos, donde se destacaban las artes. Karzhavin fue un artista, naturalista y viajero, que transitó por Europa y las Américas. Coincidiendo con su llegada a Cuba, corresponde también a 1782 la primera mención a Rusia que aparece en la prensa cubana. La Gaceta de la Habana publicó en su edición del viernes 22 de noviembre de 1782 la primera información conocida en Cuba sobre Rusia. Desde 1782 hasta 1784, Karzhavin, además de ejercer la medicina, se dedicó a la enseñanza de idiomas. Los historiadores cubanos lo reconocen como 'el primer maestro de lengua rusa'. Al regresar a su país, el médico ofreció sus impresiones sobre la isla de Cuba. ${ }^{15}$

Posteriormente el Diario de la Habana reflejó en sus páginas los acontecimientos vinculados con la guerra de invasión napoleónica. A partir de 1813 se dan a conocer, en una serie de artículos, la historia y la situación reinante en dicho país. Los primeros términos rusos como Rusia, Zar, mujik y otros, llegan al lector cubano en los tiempos del imperio Napoleónico (1804-1815), en conflicto con la autocracia zarista. Esto fue reflejado copiosamente por la prensa cubana de la época. En fecha tan temprana como 1854, el publicista cubano J. de Jesús O. García, en su artículo "Literatura Rusa" ofreció a los lectores un panorama de la misma en la primera mitad del siglo XIX. Después de caracterizar el desarrollo periodístico de Rusia, hace un análisis crítico de las obras más sobresalientes y de sus autores. En su trabajo, García, demuestra tener absoluto dominio de la lengua rusa al usar numerosos términos. ${ }^{16}$

\footnotetext{
${ }^{14}$ Sobre los rusos visitantes en Cuba sugerimos las siguientes publicaciones: Ángel García y Piotr Mironchuk. Raíces de las relaciones cubano-soviéticas (Havana: Editorial de Ciencias Sociales, 1988), Leonardo Depestre Catony 100 famosos en la Habana (Ciudad de la Habana: Editorial de Ciencias Sociales, 1999). Alexander N. Moiseev y Olga V. Egorova, Los rusos en Cuba (Ciudad de la Habana: Casa Editorial Abril, 2010).

${ }^{15}$ Sobre el artículo sobre Karzhavin consultar Brockhaus and Efron Encyclopedic Dictionary.

${ }^{16}$ También es justo recordar que en 1856, el poeta Joaquín Lorenzo Luaces publica su "Canto del Cosaco", en el que se destaca el uso de términos rusos, algunos incluso poco conocidos en la literatura de la época como: KNUT (Látigo). El crítico Aurelio Mitjans en su ensayo "Caracteres dominantes de la literatura en los últimos 50 años" se refiere a la novela rusa por su valor realista en contra del despotismo. Continuadores de la tradición por el estudio de la literatura nacional rusa son José María Collantes, quien en su trabajo "Literatura rusa, su pasado y su presente" (1904) presta especial atención a la obra de Tolstoi. De igual forma lo hace José Manuel Poveda en su artículo "Sobre Chejov" (1909).
} 


\section{José Martí, el gran transculturador de lo ruso}

Uno de los diseminadores de las artes eslavas en las Américas, en particular de lo ruso, fue el poeta e independentista José Martí. Su pensamiento ha sido tomado como esencial para el nacionalismo cubano. La comprensión por el intelecto cubano de los asuntos sobre la historia y las artes de los países de la 'otra Europa', le debe mucho a Martí. La visión martiana de la Rusia de fines del siglo XIX es algo para advertir, porque desempeñó no solo un papel predominante en el acercamiento de las culturas, también contribuyó al conocimiento del tema ruso y su literatura en las Américas. Decía Martí: "llama Rusia sobre sí natural y gravemente la atención, por la importancia de las cuestiones que promueve." 17

Como bien explicara Luis Álvarez en su estudio La cultura rusa en Martí, el interés concentrado del poeta por esta lengua, lo llevó incluso a anotar el significado léxico de una serie de vocablos rusos de la época: "isba, kvas, knout, boyardo, vodka, mujik, etc.: un desfile de términos” (Álvarez, 2010: 15). Sobre el tema ruso-martiano se destaca el artículo publicado en 1889 sobre la exposición del famoso pintor Vasili Vereshaguin (1842-1904); y sus obras inspiradas en los episodios de la guerra ruso-turca, la "imprescindible guerra por la paz". De sus escritos dedicados a la vida y obra del poeta Alexander Pushkin se conocen varias referencias martianas, por lo que no es casual que después de su muerte en los apuntes de trabajo de Martí fuera encontrado un rico vocabulario de términos rusos traducidos al español. ${ }^{18}$ Sin embargo, no hay un solo testimonio, que pudiera identificar su pensamiento con el socialismo. Es más, Martí expresó una real preocupación al respecto: "dos peligros tiene la idea socialista, como tantas otras: el de las lecturas extranjerizas, confusas e incompletas-, y el de la soberbia y rabia disimulada de los ambiciosos". ${ }^{19} \mathrm{El}$ pensamiento de Martí expresa más diferencias que simpatías por la idea socialista. A pesar de ello, en Cuba, muchos insisten en identificarlo con este ideario político. ${ }^{20} \mathrm{El}$ historiador inglés G.D.H. Cole en su estudio The Second International1889-1914. A History of Socialist Thought, sugiere acertadamente que: "los revolucionarios cubanos no eran socialistas; ni sus principales teóricos. José Martí, no conceptualizó una doctrina cubana específicamente socialista” (Cole, 1956: 838). Martí rechazó el unipartidismo, la idea errónea del 'partido único' como regente en la democracia, que fue sin duda el fundamento esencial en la ideología soviética, cuando dijo: "Siempre es desgracia para la libertad que la libertad sea un partido" (Escenas Mexicanas, 1877). No obstante, a pesar de las diferencias martianas en el método político, él fue certero al profetizar que "el ruso renovará..." algo bien evidente en las artes y en las ciencias (Martí, 1889: 429). Que mejor forma de cerrar el tema

\footnotetext{
${ }^{17}$ Artículo "El último paquete." Revista Universal. México, 3 de abril de 1875. Tomo 28 Obras Completas. página 20.

${ }^{18}$ En 1970, aparecen publicadas en Cuba, una serie de estudios dedicados a Vladimir Ilich Lenin

${ }^{19}$ Carta a Fermín Valdés Domínguez (1852-1910), en el Tomo 3, página 168. Obras Completas

${ }^{20}$ Ver Siete enfoques marxistas sobre José Martí(La Habana: Editora Política, 1978) publicado por el Departamento de Orientación Revolucionaria del Comité Central del PCC.
} 
martiano, en conexión con lo ruso literario, que dedicarle unas líneas a lo que nombro como la Homilía rusa por la palabra. Es bien reconocida esta fascinación rusa por ella (slovo).

Por los excelentes estudios dedicados al tema podemos afirmar que el número de escritos y libros que forman parte de esta gran homilía es infinito. ${ }^{21}$ Un lugar destacado en esta lista lo ocupa La magia de las palabras (Магия слов, 1909) el ensayo de Boris Nikolaevich Bugaev, más conocido por el seudónimo de Andrei Bely (1880-1934). En la opinión de muchos, Bely fue el novelista más talentoso de la "segunda generación" de escritores rusos, que surgieron del movimiento simbolista en la segunda mitad del siglo XX; en el período que es comúnmente llamado la "edad de plata" de la literatura rusa. En su ensayo La magia de las palabras, Bely afirmó que ésta es "una fuerza mágica, creadora de un mundo: cuando digo ' $Y_{0}$ ', he creado un símbolo sonoro. Yo confirmo este símbolo como algo existente. Y sólo en ese momento yo mismo me he creado. El símbolo de la imagen está conectado con la metáfora: la palabra engendra al mito; el mito engendra la religión; la religión engendra la filosofía; y la filosofía engendra el vocablo". ${ }^{22}$

\section{Cuando el ruso se convirtió en soviético: "Lenin en las letras cubanas"}

Con la llegada de las noticias de la revolución rusa, con la toma del poder político por los bolcheviques y la aparición de los Soviets en el octubre de 1917, llega a Cuba un nuevo fenómeno lingüístico: la 'lengua soviética', o sea la ideologización comunista de la lengua rusa. Con la revolución de octubre hay un cambio radical. El testimonio lingüístico es gran prueba de este hecho. Los nuevos proyectos políticos en la economía, en las artes, en toda la sociedad crean nuevas palabras, frases y términos que fundamentan el surgimiento, en el mapa geopolítico del mundo, de un experimento socio-político, el cual se reconocerá como la Unión Soviética (URSS). Con esto, palabras ya existentes en la lengua rusa se redefinirán por el factor soviético. Por ejemplo, nombres propios eslavos que adquirían una connotación política, se convierten en sinónimos de comunismo. Este es el caso del nombre del líder de la revolución bolchevique: Vladimir Ilich Lenin (1870-1924). Bajo el título Lenin en las letras cubanas (1918-1934), el ensayista Ángel Augier nos presenta un

\footnotetext{
${ }^{21}$ Existe una excelente bibliografía actualizada que se puede obtener de la gran serie de libros en inglés sobre el tema. Ver el estudio de Thomas Seifrid (2005). The word made self: Russian writings on language, 1860-1930. Ithaca: Cornell University Press. De Michael Gorham (2003) Speaking in Soviet tongues: language culture and the politics of voice in revolutionary Russia. DeKalb, Ill.: Northern Illinois University Press. También ver de Nicholas P. Vakar, (1966). A word count of spoken Russian: the Soviet usage. Columbus: Ohio State University Press. Sobre su uso en el cine ver: editado por Stephen Hutchings y Anat Vernitski (2005). Russian and Soviet film adaptations of literature, 1900-2001: screening the word. London; New York: Routledge Curzon.

${ }^{22}$ En lengua inglesa, existe un buen número de traducciones y libros publicados sobre/por los simbolistas rusos. No es así en traducciones o estudios en español. De Andrei Belyi encontré varias ediciones en español de su novela más famosa Petersburgo (también traducida como San Petersburgo). Esta obra es a menudo comparada al Ulysses de James Joyce. Otras destacadas novelas suyas son La paloma de plata y Yo, Kótik Letáie.
} 
estudio sobre las primeras hojas impresas en Cuba dedicadas a Lenin y a su revolución. A pesar de la marcada ortodoxia comunista de Augier, este texto es ciertamente notable, válido de tener en consideración por los estudiosos, por ser de las primeras interpretaciones cubanas sobre la revolución rusa de 1917, su lenguaje y sus símbolos. ${ }^{23}$

Si antes, la mayoría de los términos rusos adquiridos en el español de Cuba, se refería a la naturaleza, a lo natural ruso, como: Siberia, taiga, Volga; con la llegada de los Soviets, nuevos vocablos aparecen: Koljoz, Gulag, Sputnik, entre tantos otros. El vocablo soviético o newspeak magistralmente detallado por el escritor británico Orwell en su novela 1984 - surgió a partir de la fusión del léxico marxista con su variante soviética. El Newspeak de Orwell no es más que una versión literaria extremadamente simplificada de un fenómeno real lingüístico iniciado con el bolchevismo de Lenin y consolidado con el poder soviético de Stalin. La historia de la lengua marxista-leninista, como la leyenda de la Torre de Babel, reposa sobre una realidad. En efecto, existe un documento histórico, dictado por Joseph Stalin que fundamentó los principios de esta 'nueva' lengua, en su manifiesto Acerca del marxismo en la lingüistica. ${ }^{24}$ Sin dudas, este es un texto fundamental que explica la llamada 'dictadura del proletariado' del partido comunista y del Soviet Supremo de la URSS.

A la pregunta: ¿qué ha cambiado desde entonces en la lengua rusa? Stalin responde: "ha cambiado en cierta medida el vocabulario de la lengua rusa. Ha cambiado en el sentido de que se ha visto enriquecido con un considerable número de nuevas palabras y expresiones nacidas con la nueva producción socialista, con el nuevo estado, con la nueva cultura socialista, con las nuevas relaciones sociales, con la nueva moral y finalmente, con el desarrollo de la técnica y de la ciencia, muchas palabras y expresiones han cambiado de sentido y adquirido una significación nueva." ${ }^{25}$ Ciertamente, el objetivo de crearla no era sólo para sustituir al "viejo" ruso tradicional por otro nuevo, como parte del cambio radical experimentado, como reflejo/imagen del momento histórico en que se vivía, pero sobretodo, era un intento de unificación lingüística como propuesta universal, el poder uniformar y dominar el pensamiento de todos los miembros de la sociedad, para hacer inviables otras formas disidentes o antagónicas a los principios del marxismo-leninismo. Como la misma leyenda de la Torre de Babel, esta nueva de la ideología soviética y su vocablo, es una de las más famosas en la historia

\footnotetext{
${ }^{23}$ Sobre esta temática ver también: La Revolución de Octubre y su repercusión en Cuba, editado by Erasmo Dumpierre (La Habana: Editorial de Ciencias Sociales, 1977). Felipe Pérez Cruz, Mella y la Revolución de Octubre (Ciudad de La Habana: Editorial Gente Nueva, 1980), Mirta Aguirre, El leninismo en 'La historia me absolverá' (La Habana: Ciencias Sociales, 1980), and Olivia Miranda, 'Lenin y la Revolución de Octubre en la Cuba Colonial', in Marx Ahora, no 24/2007 pp. 160-80. También de Mirta Aguirre, Cuba y la Revolución de Octubre (Ciudad de La Habana: Editorial de Ciencias Sociales, 1980).

24 Para una versión online del texto de Stalin Acerca del marxismo en la lingüística, ver 'Scribd, the world's digital library', consultado 10.01.2015.

${ }^{25}$ Ver versión online del texto de Stalin Acerca del marxismo en la lingüística. (Consultado el 15.01.2015).
} 
universal, y en sus estudios del origen de las lenguas. Para el lector de hoy, podría parecer un tanto absurda. Sin embargo, poniéndose en el contexto de las creencias políticas de la época, éstas explican muchas cosas que podrían parecer extrañas en un primer análisis. ${ }^{26}$

En 1917, llegó a la isla de Cuba la noticia de una revolución en un país lejano y desconocido: Rusia. La revolución de octubre marcó el fin de la dinastía Romanov, que gobernó el país durante casi trescientos años. Este hecho y la personalidad de Lenin atrajeron a muchas personas alrededor del mundo, que creían que este proceso traería una verdadera solución a la desigualdad social. En el caso de Cuba, el ideal soviético tuvo una recepción inmediata en los pequeños grupos, en los políticos más radicales, particularmente entre aquellos artistas e intelectuales que estaban buscando una perspectiva que rescatara a Cuba de su sumisión política y económica a los Estados Unidos. Una difícil situación social interna, agravada durante este período, proporcionó el mejor ambiente para la difusión en la isla de ideas radicales como el marxismo, en su versión soviética. Como es sabido, en América Latina, el movimiento comunista apareció como un fenómeno surgido de la revolución de octubre en Rusia. Este fue el caso del primer partido socialista cubano. Carlos Baliño ha sido reconocido como el primer marxista en la historia de Cuba. Su nombre recuerda la fundación del primer partido comunista con Julio Antonio Mella (1925). Antes de 1959, Baliño era un desconocido, su nombre nunca apareció en los libros de historia o literatura en general. Este hecho demuestra lo débil que era la presencia comunista en la vida intelectual de la isla. Sin embargo, él es una personalidad clave en nuestra historia, pues vincula dos grandes generaciones del pensamiento político cubano: el nacionalismo (patriotismo) y la ideología soviética. La conexión de Baliño con Martí ofrece una gran oportunidad para el reconocimiento popular de las ideas comunistas. Con él, Baliño fundó el Partido Revolucionario cubano en 1892. Esta clave conexión martiana fue bien conocida por aquellas personas en Cuba, que trabajaban para el Kremlin soviético. Durante todo el período antes de 1959, el principal promotor y difusor en la cultura soviética en Cuba fue el Partido Socialista (PS). La creación de este partido político es el más importante ejemplo del impacto inmediato de la revolución de octubre en Cuba. ${ }^{27}$

En su tiempo, Lenin reconoció la enorme trascendencia social de este medio. El líder de la revolución de octubre afirmó: "de todas las artes, el cine es, para nosotros, la más importante" (Taylor, 2002: 57). Desde el principio, los comunistas cubanos utilizaron al llamado

\footnotetext{
${ }^{26}$ La leyenda de la Torre de Babel es una de las más famosas narrada en el Génesis que contiene la Biblia: "He aquí que todos forman un solo pueblo y todos hablan una misma lengua, siendo este el principio de sus empresas. Nada les impedirá que lleven a cabo todo lo que se propongan. Pues bien, descendamos y allí mismo confundamos su lenguaje de modo que no se entiendan los unos con los otros». Así, Yahveh los dispersó de allí sobre toda la faz de la Tierra y cesaron en la construcción de la ciudad. Por ello se la llamó Babel, porque allí confundió Yahveh la lengua de todos los habitantes de la Tierra y los dispersó por toda la superficie." Génesis 11:1-9.

${ }^{27}$ Por un estudio sobre Baliño, ver Carmen Gómez García, Carlos Baliño: Primer pensador marxista cubano, un estudio de su pensamiento filosófico y social (La Habana: Editorial de Ciencias Sociales, 1985). Ver también el estudio de Jorge García Montes y Antonio Alonso, Ávila (1970) Historia del Partido Comunista de Cuba. Miami: Ediciones Universal.
} 
‘séptimo arte’ como el arma más eficaz para diseminar la ideológica soviética en la capital cubana. Gracias al cine, las obras de los exponentes más transcendentales de la estética soviética, en particular los colosos del 'realismo socialista' se pusieron en circulación. Desde el Chapaev de Furmanov hasta El destino de un hombre de Sholokhov, pasando por la novela Cemento de Fyodor Gladkov, hasta Cómo se templó el acero de Nikolai Ostrovsky, todas estas obras literarias tuvieron sus adaptaciones cinematográficas en la URSS y fueron además exhibidas en Cuba desde los tiempos de los cursos pioneros de cine impartidos por Manuel Valdés Rodríguez en la Universidad de la Habana (Valdés, 1966). Esta experiencia fue una manera renovada de celebrar la palabra rusa y en particular la mejor forma de fusionarla con el proyecto comunista, una manera eficaz de visualizar y diseminar el vocablo soviético, pues 'el cine es el único libro que pueden leer hasta los analfabetos'.

Estudios recientes destacan la gran relevancia actual, el importante legado y contribución intelectual de Fernando Ortiz, ignorando un hecho importante: el especial interés de Ortiz en la cultura rusa en el periodo soviético. ${ }^{28}$ En 1945, él se convirtió en presidente del Instituto de Intercambio Cultural Cubano-Soviético. Sin dudas, un importante capítulo en los vínculos culturales, fue su publicación: Cuba y la URSS (1945-52). Esta fue pionera como diseminadora del vocablo soviético en el mundo hispano de las Américas. Entre sus innumerables actividades, propició la organización de exposiciones de las artes soviéticas, retrospectivas fílmicas y cursos gratuitos de idioma ruso impartidos por Sonia Pogolotti. ${ }^{29}$ Entre sus miembros estuvieron, entre otros, José M. Valdés Rodríguez, Emilio Roig de Leuchsenring y Nicolás Guillén. En el primer número de la revista del Instituto, exclama Ortiz: “¡Venga a Cuba la afluencia de esa joven cultura con sus positivos valores de experiencia”. ${ }^{30}$

$\mathrm{Al}$ analizar esta declaración, hay dos puntos a tener en cuenta. En primer lugar, la descripción de la cultura soviética como 'joven' en lugar de 'nueva', como los comunistas preferirían llamarla. Ortiz celebró la juventud de la cultura soviética, entendida desde la perspectiva transcultural que reconoce un cambio dentro del proceso continuo de la cultura. En segundo lugar, como humanista, Ortiz examinó la necesidad esencial de estar en contacto con los más variados discursos culturales, no sólo para entender a los demás, sino también para ser entendido por otros. Hoy en día, muchos malinterpretan o restan importancia a la asociación de Ortiz con los comunistas. Para él, la creación

\footnotetext{
${ }^{28}$ Ver Cuban Counterpoints: the legacy of Fernando Ortiz. Edited by Mauricio A. Font and Alfonso W. Quiroz (Lanham: Lexington Books, 2005).

${ }^{29}$ Sobre la historia del Instituto de Intercambio Cultural Cubano-Soviético, ver Migdalia Pérez Cabrera, 'Un símbolo de amistad: la revista Cuba y la URSS', Anuario Literatura y Lingǘśstica (La Habana), nos. 7-8, (1976-77), pp. 303-5.

${ }^{30}$ En un artículo titulado 'Más contacto de las culturas', que apareció en el primer número de la revista "Cuba y la URSS”, Ortiz explica las razones para la creación de este Instituto: “iVenga a Cuba la afluencia de esa joven cultura con sus positivos valores de experiencia y de esperanzas! A la conciencia nacional cubana corresponde aceptarla o desoírla y en todo caso decidir por su propio juicio, premeditado y libre, pecado ignorancias ya inexcusables ni presiones ajenas que, vengan de donde fuere, siempre hijo repulsivas." Ver Fernando Ortiz, 'Más contacto de las culturas', Revista Cuba y la URSS, no. 1, La Habana, Agosto 1945, p.27
} 
de esta institución era otra manera de animar el necesario intercambio entre culturas, incluyendo aquella distante, producida en la Unión Soviética. Por otro lado, la conceptualización de Ortiz de la cultura demostró ser alternativa al concepto de la sociedad, dominante en la teoría marxista-leninista. Mientras que, ésta ideología divide a la sociedad en clases y partidos, cada uno luchando por la supremacía, para Ortiz, sólo la cultura posee el potencial de unir a las personas, trascendiendo los límites, fronteras sociales, étnicos, nacionales e ideológicos. Sin duda, el enfoque transcultural de Ortiz fue diferente dentro de la historia de la ofensiva cultural soviética en el hemisferio occidental.

\section{Segunda Época:}

\section{Fidel Castro, el gran transculturador de lo soviético}

1959 marca el final de la dictadura de Batista y la entrada en la Habana del Comandante y sus barbudos. Este segundo período es el que marca la inserción definitiva del vocablo soviético en el español cubano y comienza a partir de 1961. La declaración del carácter socialista de la revolución cubana establece ‘oficialmente’ la inserción de lo soviético en lo cubano. Además de palabras del ruso tradicional se agregan nuevas palabras que llegan hasta finales de los ochentas, como las internacionalmente conocidas perestroika y glasnost. En esta época, los vínculos entre los gobiernos, entre el Kremlin y la Habana se profundizan, surgen diferentes instituciones que contribuyen al acercamiento cultural. Es así como el escritor y colaborador de la Revista Avance, Adia M. Yunkers, residente entonces en Cuba, imparte los primeros cursos de idioma ruso.

Es oportuno recordar que al completar la campaña de alfabetización, la misión de llevar la educación a los rincones más apartados y olvidados de la isla, los jóvenes alfabetizadores se reunieron en la histórica Plaza a la espera de un nuevo llamamiento en apoyo de la revolución. Fidel Castro anunció la creación del nuevo plan de formación de maestros sin precedente en ningún otro país en las Américas, y con esto el aprendizaje masivo, a nivel nacional del idioma ruso. El país que recibía apoyo y colaboración de la URSS, necesitaba traductores. Además de los cientos de miles de cubanos que estudiaron en la Unión Soviética, en 1961, se anuncia en un discurso que miles de graduados de secundaria se formarían como instructores del idioma ruso. Un año después, la escuela se transformó. En enero de 1962 fue fundado el Instituto del idioma ruso Máximo Gorki. ${ }^{31}$ Durante los años ' 60 y ' 70, el ruso, junto al inglés, eran asignaturas optativas, tanto en la enseñanza secundaria como en el bachillerato. También se enseñaba ruso a través de programas de radio y televisión. En la década de los '80, el estudio del idioma ruso pasó a ser obligatorio en la enseñanza universitaria.

\footnotetext{
31 Más tarde, con la ampliación de sus horizontes a otras lenguas extranjeras, se convirtió en el Instituto de Idiomas Extranjeros de Máximo Gorki.
} 
Como es bien conocido, después de 1961, casi la totalidad de la cultura material disponible (tecnología, bienes de consumo, el transporte público) procedía de los países del bloque soviético. Cuba se convirtió en un miembro activo de la CAME (Consejo de Ayuda Mutua Económica) en julio de 1972. Las cosechadoras de caña, los tractores, una gran parte de los medios cubanos de transporte, militar y civil, la tecnología y el equipo, eran todos de fabricación soviética. Los monumentos dedicados a los líderes de la URSS y los edificios de estilo soviético fueron construidos al este de la capital cubana. Esta área fue bautizada por el argot popular como la Siberia. Así se añadió lo soviético arquitectónico a la larga tradición ecléctica de la isla.

La terminología y conceptos soviéticos se hicieron familiares a los cubanos. Ya sea en la asamblea de la escuela primaria o la reunión sindical, el lenguaje político, el vocablo soviético se convirtió en la norma. ${ }^{32}$ Los hábitos de lectura tradicional cubana cambiaron con la incorporación de temas soviéticos que iba desde los libros infantiles a la literatura para adultos; la televisión, y el cine. Con el socialismo llegaron las nacionalizaciones. Los medios de comunicación estuvieron entre los primeros afectados. En el caso del cine, García Espinosa recuerda que 'si queríamos iniciar, de verdad, un cine nacional, teníamos que nacionalizar' (García, 1982: 96). Grandes problemas se establecieron con esta prematura y desacertada decisión. En ese tiempo, contaba Cuba con una gran cadena de cines modernos en la capital, pero no había películas para exhibir, pues se les cerró las puertas al cine de Hollywood, que era el gran proveedor hasta ese momento. Por esto, y para explicarlo en las propias palabras de García Espinosa: 'Las películas soviéticas vinieron en cantidades exorbitantes, segundo la mayoría era bastante mala y tercero aquel era un cine al cual la gente no estaba acostumbrada. El público estaba acostumbrado al ritmo de las películas americanas; así que hubo un rechazo. Ese fue el costo de mantener abierto las salas de cine” (Fowler, 1996: 180-181).

Ante el fracaso, el cine soviético fue llevado a la televisión cubana. Mario Rodríguez Alemán fue el encargado de este proyecto. El film Acorazado Potemkin de Sergei Eisenstein fue el escogido para presentar, el 5 de noviembre de 1959, el primer programa de la televisión cubana dedicado a la crítica de cinematográfica: Cine en TV (1959-1977). ${ }^{33}$ Esta fue la primera expresión de un movimiento radical en nuestra televisión que ya era una gran innovadora en Latinoamérica. Cuba cambió de canales: no más TV comercial pero televisión al estilo soviético, no más del sueño norteamericano, sino más bien pura ilusión soviética. La televisión cubana asumió el papel que el ICAIC, el instituto del cine, no pudo poner en práctica: ser el principal difusor de las películas de los países del bloque, y con estos diseminar el mensaje soviético en Cuba. Como vemos, cada aspecto de la vida cubana fue influenciado por el vocablo soviético. Sin dudas, los cubanos se enfrentaron ante una cultura que era hasta entonces desconocida y ajena, proveniente de los países del bloque del este

\footnotetext{
32 Ver José Antonio Portuondo (1979). Orden del día. Ciudad Habana: Ediciones Unión.

${ }^{33}$ Ver Rolando Pérez Betancourt, 'Mario en los 60’, periódico Granma (12 Junio 1986), p. 4.
} 
europeo. Generaciones nuestras fueron educadas de acuerdo con los principios del marxismoleninismo. ${ }^{34}$

Otro gran ejemplo del intercambio cultural fue el programa nuclear cubano en Juraguá; también los profesionales, que estudiaron en las instituciones académicas y politécnicas de los países del bloque. En este contexto, una nueva experiencia sexual y un nuevo tipo de familia nacieron. En su gran mayoría fueron relaciones entre hombres cubanos y mujeres soviéticas. Los nombres eslavos fueron muy populares entre los nacidos en las dos primeras décadas de la revolución. Un gran número de ellos fueron llamados por los líderes revolucionarios rusos, muchos llevan los nombres eslavos de personajes reales y literarios.

Las fuerzas militares cubanas fueron re-organizadas bajo el modelo soviético. Las Fuerzas Armadas Revolucionarias (FAR) no son más que una adaptación caribeña del desaparecido ejército rojo soviético. Esto fue reconocido por el propio general Raúl Castro, actual presidente de Cuba, en sus palabras introductorias al libro Valentía y fraternidad (Shkadov, 1983). Esta publicación es la historia del surgimiento del llamado 'ejército de nuevo tipo' en Cuba, excelente crónica testimonial, documento histórico que evidencia la estrecha colaboración con la URSS en la esfera militar. Un momento cumbre de esta historia se alcanzó el día, cuando a bordo de la Soyuz 38 de la Fuerza Aérea, el coronel Arnaldo Tamayo Méndez se convierte en el primer afro-cubano en llegar al espacio cósmico el 18 de septiembre de 1980. Esta fue la séptima tripulación internacional del programa INTERCOSMOS (Caballero, 1981). Las organizaciones de masas y el nuevo tipo de sociedad civil de apoyo a la revolución cubana, fueron creadas siguiendo el modelo soviético. Las muy famosas "casas de cultura" emergieron como nuevos elementos en la sociedad cubana como una actividad organizada por el partido comunista como parte del proyecto cultural en el llamado 'trabajo ideológico', donde se trataba la socialización de los adultos y los niños en su tiempo libre, a través de la participación en la cultura no profesional y otras actividades culturales. El idioma ruso, y en particular su vocablo soviético, hasta ese momento desconocido por la mayoría de la población, se convirtió en el más promovido en los programas educativos cubanos. Ya no era el inglés, sino el ruso el idioma del futuro. Ciertamente, la adopción lingüística desde la lengua rusa tuvo un carácter mediático. Comenzó en tiempos de la colonia, con el periodismo fundamentalmente, y después se diseminó gracias al cine y en particular por medio del ICRT, la televisión socialista de Fidel Castro. Como bien diría el cineasta Julio García Espinosa, en Cuba, 'los cuatro medios de comunicación son tres: cine y TV'.

\footnotetext{
${ }^{34}$ Sobre estos eventos ver Jonathan Benjamin Alvarado, Power to the People: Energy and the Cuban Nuclear Program (New York and London: Routledge, 2000); ver la antologia editada por Jacqueline Loss sobre lo soviético en la cultura cubana: Caviar with Rum: Cuba-USSR and the post-Soviet Experience (New York: Palgrave, 2011). También sobre la época postsoviética cubana ver el libro Escrito en cirilico. El ideal soviético en la cultura cubana posnoventa, de Damaris Puñales-Alpízar (Santiago de Chile: Editorial Cuarto Propio, 2012) y mi tesis doctoral, KinoCuban: the significance of Soviet and East European cinemas for the Cuban moving image. (University College London).
} 
En conclusión podemos afirmar que las adopciones léxicas desde la lengua rusa se pueden clasificar de la siguiente forma:

1. Adopción léxica: Se incorporaron la morfología y el significado de una palabra perteneciente al ruso. Esta adopción implica una adaptación de la pronunciación original y casi siempre de la representación ortográfica. Por ejemplo de Tsar a Zar, Perestroika, Glasnost. Si se reproduce respetando enteramente tanto su sonido como su escritura, se denomina xenismo, es el caso de muchos nombres propios como Kino, Tatiana, Boris, Volga o de objetos Lada, Sputnik. ${ }^{1}$

2. Adopción semántica: Cuando una misma palabra existe en dos idiomas, y en la imitada posee un significado o acepción que en la otra no existe, y se copia esa acepción o significado en la lengua que no lo posee, se está realizando un adopción semántico, por ejemplo, las palabras pioneros ya existía en español, pero no con el significado marxista-leninista.

3. Calco semántico: Se incorpora el significado de una palabra extranjera traduciéndola; por ejemplo, el Дворец пионеров se traduce por la expresión " Palacios de los Pioneros", o "Casa de cultura" (Дот культуры, dom kultury).

4. Acrónimos, también sirve para designar no sólo la adopción/adaptación de palabras, que pueden ser una sigla que se pronuncia como una palabra -y que por el uso acaba por incorporarse al léxico habitual en la mayoría de casos. En este grupo de acrónimos también deben mencionarse las de las organizaciones de masas, políticas, de seguridad y militares existentes en Cuba creadas como calcos de organizaciones soviéticas como son: como la UNEAC (Unión Nacional de Escritores y Artistas de Cuba, la UJC (Unión de Jóvenes Comunistas), ANAP (Asociación Nacional de Agricultores Pequeños), OPJM (Organización de Pioneros José Martí), la FMC (Federación de Mujeres de Cuba), FAR (Fuerzas armadas revolucionarias) y el MININT (Ministerio del Interior) y el Departamento de Seguridad del Estado, más conocido como G2 que pueden ser estructuras gramaticales, o un vocablo formado al unir parte de dos palabras, dos letras, letras y números. Por ejemplo, el UMAP (Unidades Militares de Ayuda a la Producción) como fenómeno único en Cuba fue un calco del lenguaje político nacido del sistema represivo soviético reconocido como GULAG (ГУЛАГ, Главное управление исправительно-трудовых лагерей и колоний, Dirección General de Correctivos y Colonias de Trabajo.

Estos vocablos no son sólo referencias filológicas, símbolos de una oralidad y escritura muy particulares, también son evidencias históricas, que actúan como códigos de acceso a la experiencia cultural soviética. Todas estas palabras no sólo son referencias al elemento eslavo-ruso en el español cubano actual, también son evidencias, códigos de acceso a la experiencia soviética en general, y en 
particular a su período en la historia de Cuba. Sin dudas, estas palabras, que llegaron en diferentes épocas, ya forman parte del fenómeno cubano de 'adopción' lingüística, de los extranjerismos en nuestro catauro caribeño.

\section{A modo de conclusión: Nostalgia, lo Soviético y Cuba (principios del Siglo XXI)}

El ambiente post-soviético en la Europa del este se ha descrito por algunos estudiosos como nostálgico. Muchos ya incluyen esta experiencia como parte de los estudios postcoloniales. Sin dudas, un gran capítulo dedicado al tema de la nostalgia como nuevo fenómeno político-social, se va conformando en el tiempo. ${ }^{35}$ Aquellos que recuerdan con tristeza el cercano pasado, debaten en una encrucijada, entre el rechazo y la aceptación de lo soviético. Esta situación fue bien descrita por Vladimir Putin, el actual presidente de Rusia, cuando dijo: 'la persona que no se arrepiente del colapso de la Unión Soviética no tiene corazón. La persona que lo desee restaurado no tiene cerebro." 36

En Cuba, ¿hay nostalgia por lo soviético? Soy de los que piensan que en nuestro caso existe el recuerdo, la memoria que vive en una atmósfera de gratitud y reconocimiento por lo positivo, siendo crítico al mismo tiempo por lo desacertado. En este repaso histórico, se destaca lo que fue progresista y renovador. Identificamos a los dos grandes transculturadores del vocablo ruso-soviético en Cuba: José Martí (de lo ruso) y Fidel Castro (de lo soviético). Ellos como pensadores políticos, lograron como nadie, 'transcultural' el mundo ruso-soviético dentro del cubano, hasta ese entonces dominado por la cultura europea occidental y la de Norteamérica. Ellos lograron a nivel intelectual una integración entre ambos mundos que en la realidad histórica no se había consumado antes; y ya es parte de nuestra identidad. Todo esto es resultado del continuo proceso de transculturación. Por eso, no es extraño ver agradables encuentros culturales que estudian este momento, nuevos proyectos bilaterales, multinacionales, como éste en el cual participamos hoy. Con la desaparición del Soviet Supremo, consecuente con la caída del muro de Berlín, del bloque soviético en la Europa del este y con las restablecidas relaciones diplomáticas con los Estados Unidos, el ex gobernante Fidel Castro y el actual presidente - su hermano Raúl - animan al presente cubano a estudiar inglés. De alguna forma se lamentan no tanto por lo soviético, sino por haber 'perdido el tiempo' aprendiendo ruso. En la evocación del pasado soviético, utilizar la palabra nostalgia para referirse al caso cubano, es algo ciertamente equívoco, como este texto ha querido demostrar.

\footnotetext{
36 Ciertamente, con la desmesurada privatización, dictada por la política neoliberal, se destruía lo mejor del legado soviético: el derecho gratuito a la salud, a la educación y la posibilidad de una seguridad social efectiva.

Ver el proyecto online de la University of Leeds: Post-Communist Nostalgia in Poland, Hungary and East Germany consultado (10.01.2015)De 'Vladimir Putin. Entrevista ofrecida a la televisión alemana (ARD y ZDF)'. Mayo 5, 2005 (consultado 11.01.2015).
} 
El experimento soviético, desde la perspectiva lingüística transcultural, se nos presenta como la famosa historia bíblica de La torre de Babel. Gracias a las fabulosas imágenes que existen hoy, tanto en lo científico como en lo artístico, hoy podemos afirmar que su vocablo, como la leyenda de la torre, fue construido con gran sacrificio y su difusión sobrevivió poco tiempo. Tuvo su momento, cuando el proyecto soviético en el mundo socialista 'tenía una misma lengua y usaba las mismas palabras'. Este vocablo no sólo resume la peripecia de una epopeya humana (que nos parece por momentos absurda), pero también la cronología de su colapso. Todo envuelto de historias y mitos de supervivencia, de iconos ideológicos, de limitaciones, censuras y de incendios fatídicos. Lo más importante para nosotros es reafirmar que con la pérdida de la lengua única -la soviética-se regresó a la diversidad de lenguas, el retorno de lo vernáculo.

En el caso cubano, parece ser el regreso al proyecto original de la revolución, aquella que llegó a la Habana en enero de 1959. La pérdida de lo obsoleto, de lo que funcionó solo en palabras, no debe ser vista con tristeza, con nostalgia, como castigo. Esta pérdida es al mismo tiempo un don, pues también define y proyecta a la mujer y al hombre en sus posibilidades infinitas. El vocablo soviético ciertamente restringió la libertad de movimiento, de elección. Sin dudas, limitó la imaginación del intelecto, reduciendo toda acción a lo que debía ser aceptado políticamente. Si la pérdida es un castigo, es entonces como el castigo bíblico de Adán y Eva, pues abre las posibilidades a nuevas opciones. La confusión, nostalgia que pueda existir por la desaparición de esta lengua única, debe sugerirnos, implica la posibilidad de volver a aprender. El individuo debe andar por su propio camino, lleno de contradicciones, reconociéndolas, hasta encontrar la claridad que le haga dejar atrás el odio y la confrontación del pasado. Solo así, el ser humano podrá superar su propia confusión y nostalgia. Aprendiendo su propia lengua que a la vez le identifique con el prójimo.

Lo soviético no fue una utopía perdida, sino una ilusión. Una práctica que marcó la vida de generaciones alrededor del mundo, una experiencia cultural que creó y destruyó personas e instituciones. Un sueño soñado por muchos, pesadilla sufrida por otros. En teoría, se trataba de un proyecto revolucionario, humanista y progresista. La realidad vivida, su diario no fue enteramente así. Ciertamente, aquel experimento ya forma parte de la memoria histórica de Cuba, es fracción de nuestras remembranzas, pero no es algo que se recuerda con tristeza pues todavía no pertenece por entero al pasado. No es una dicha perdida como es interpretada por los cronistas de la nostalgia en la Europa del este actual.

A pesar de todo, y en contra de todos los pronósticos, Cuba continua orgullosa, pregonando sus llamadas 'conquistas revolucionarias', en el terreno de la salud, la educación y la seguridad social, puntales esenciales del proyecto llegado desde la URSS. Como conclusión, podemos afirmar que el vocablo soviético representó a una ideología que pretendió ser distinguida como filosofía, pero sin dudas, ya él está insertado en el gran catauro de extranjerismos del español cubano.

Londres, Febrero 2015. 


\section{Bibliografía citada}

Aguirre, Mirta (1980a). Cuba y la Revolución de Octubre. La Habana: Editorial de Ciencias Sociales.

Aguirre, Mirta (1980b). El leninismo en 'La historia me absolverá. La Habana: Editorial de Ciencias Sociales.

Álvarez Álvarez, Luis (2010). La cultura rusa en Martí. Camagüey: Editorial Ácana.

Andrews, Ernest (ed.) (2011). Legacies of Totalitarian Language in the Discourse Culture of the Post-totalitarian era: the Case of Eastern Europe, Russia, and China. Lanham: Lexington Books.

Angé, Olivia y Berliner, David (eds.) (2014). Anthropology and Nostalgia. New York: Berghahn Books.

Augier, Angel. 'Lenin en las letras cubanas', Anuario L/L 1(1970): 220-259.

Barnet Freixas, Ricardo (2002). Europa del este: el colapso. La Habana: Editorial de Ciencias Sociales.

Brandist, Craig y Chown, Katya (eds.) (2010). Politics and the Theory of Language in the USSR, 1917-1938: the Birth of Sociological Linguistics. London: Anthem Press.

Cabrera Infante, Guillermo (1992). Mea Cuba. Madrid: Alfaguara.

Cantón Navarro, José (2008). Una revolución martiana y marxista. La Habana: Centro de Estudios Martianos.

Carbonell, Néstor T. (1989). And the Russians Stayed. The Sovietisation of Cuba: A Personal Portrait. New York: Morro.

Cardoso, Eliana A. (1992). Cuba after Communism. Massachusetts: The MIT Press.

Cardoso, Mayra y Parson, Tania. "Nuestro Tiempo en la cultura cubana”. TEMAS 1(1983).

Castro Ruz, Fidel (1970). Discurso en el centenario del natalicio de Lenin. Ciudad Habana: Ediciones COR.

Centro de Estudios Martianos (ed.) (2001). José Martí : Obras Completas (CDROM). Ciudad de la Habana: Centro de Estudios Martianos, Fundación Karisma.

Choy López, Luis Roberto (1999). Periodización y orígenes en la historia del español de Cuba. Valencia: Universitat de València, Departamento de Filología. 
Cole, G.D.H. (1970). A History of Socialist Thought vol. 3, part. 2. London: Macmillan.

Comisión de Orientación Revolucionaria de la Dirección Nacional del PURSC (1963). Fidel en la URSS. La Habana: Dirección Nacional del PURSC.

Departamento de Orientación Revolucionaria del Comité Central del PCC (1978). Siete enfoques marxistas sobre José Martí. La Habana: Editora Política.

Dumpierre, Erasmo (1977). La Revolución de Octubre y su repercusión en Cuba. La Habana: Editorial de Ciencias Sociales,

Fitzgerald, Frank T. “The ‘Sovietization of Cuba Thesis’ Revisited”. Science \& Society vol. 51, n. o 4 $(1987 / 1988)$.

Font, Mauricio A, Alfonso W. Quiroz (eds.) (2005). Cuban Counterpoints: the Legacy of Fernando Ortiz. Oxford: Lexington Books.

García Montes, Jorge y Ávila, Antonio Alonso (1970). Historia del Partido Comunista de Cuba. Miami: Ediciones Universal.

García, Ángel y Mironchuk, Piotr (1988). Raíces de las relaciones cubano-soviéticas. Ciudad Habana: Editorial de Ciencias Sociales.

Gómez García, Carmen (1985). Carlos Baliño: primer pensador marxista cubano, un estudio de su pensamiento filosófico y social. Ciudad Habana: Editorial de Ciencias Sociales.

Gorbachov, Mikhail (1988). La perestroika y la nueva mentalidad para nuestro país y para el mundo entera. La Habana: Editora Política.

Grimardi Pérez, Ernestina (eda.) (1977). Bibliografía de autores soviéticos: libros y folletos publicados en Cuba, 1959-1977. La Habana: Biblioteca Nacional José Martí.

Hernández Otero, Luis y Serpa, Enrique. "Proyecciones e iniciativas culturales de los comunistas cubanos (1936-58)”. TEMAS núm. extraordinario 22-23 (2000): 88-100.

Hernández Otero, Ricardo Luis (2002). Sociedad cultural Nuestro Tiempo: resistencia y acción. Ciudad Habana: Editorial Letras Cubanas.

ICRT (ed.) (1990). Televisión cubana: cuarenta años de una seña. La Habana: Dirección de Divulgación y Relaciones Públicas Televisión Cubana.

Kautsky, John H., (2002). Marxism and Leninism: Different Ideologies: an Essay in the Sociology of Knowledge. New Brunswick, N.J.: Transaction Publishers. 
Loss, Jacqueline y Prieto, José Manuel (2011). Caviar with Rum: Cuba-USSR and the post-Soviet Experience. New York: Palgrave,

Luis, William (2003). Lunes de Revolución: literatura y cultura en los primeros años de la Revolución Cubana. Madrid: Editorial Verbum.

Marx Ahora (comp.) (2006). Camino a lo alto: aproximaciones marxistas a José Martí. La Habana: Editorial de Ciencias Sociales.

Moiseev, Alexander y Egórova, Olga (2010). Los rusos en Cuba: crónicas históricas, juicios y testimonios. La Habana: Casa Editora Abril.

Mosquera, Gerardo (1989). El diseño se definió en Octubre. La Habana: Editorial Arte y Literatura.

Nabel Pérez, Blas et alii (eds.) (2010). Cincuenta añosjuntos. La Habana: Embajada de la Federación de Rusia en Cuba.

Ortiz López, Luis A. (1999). El Caribe hispánico, perspectivas lingüísticas actuales: homenaje a Manuel Álvarez Nazario. Madrid: Iberoamericana.

Ortiz, Fernando (2002). Contrapunteo cubano del tabaco y el azúcar. Madrid: Cátedra.

Ortiz, Fernando (1945). 'Más contacto de las culturas’, Revista Cuba y la URSS, agosto.

Paz, Carlos (1994). Diccionario cubano de términos populares y vulgares. La Habana: Editorial de Ciencias Sociales.

Pérez Cabrera, Migdalia. “Un símbolo de amistad: la revista Cuba y la URSS”. Anuario Literatura y Lingüística 7-8, (1976-77): 303-5.

Pérez Cruz, Felipe (1980). Mella y la Revolución de Octubre. La Habana: Editorial Gente Nueva.

Pérez Martin, Ezequiel. “Ese hombre que enseña a ver cine: Mario Rodríguez Alemán ayer y hoy”. Bohemia (1985): 16-20.

Portuondo, José (1979). Orden del día. La Habana: Ediciones Unión.

Prieto Jiménez, Abel (1997). El humor de Misha: la crisis del "socialismo real" en el chiste político. Buenos Aires: Ediciones Colihue.

Timroth, Wilhelm von. (1986). Russian and Soviet sociolinguistics and taboo varieties of the Russian language: (argot, jargon, slang, and "mat"). München: O. Sagner.

Todorova, Maria y Zsuzsa, Gille (2010). Post-communist nostalgia. New York: Berghahn Books. 